\title{
Innovation capabilities in agribusiness: evidence from Brazil
}

\author{
Ricardo Machado Leo, Guilherme Freitas Camboim, \\ Ariane Mello Silva Avila, Fernanda Maciel Reichert and \\ Paulo Antônio Zawislak \\ Universidade Federal do Rio Grande do Sul, Escola de Administração, \\ Porto Alegre, Brazil
}

\begin{abstract}
Purpose - This paper aims to identify the winning combination of innovation capabilities for selected Brazilian agribusiness firms along different value chain links.

Design/methodology/approach - Adopting a quantitative approach, the authors analyzed the relationship between innovation capabilities and innovative performance of 300 agribusiness firms through a multi-regression technique.

Findings - The results showed that transaction, management and development capabilities can improve agribusiness firms' performance in underdeveloped value chains.

Research limitations/implications - For future research, the authors recommend analyzing further links such as traders and retailers to find the innovation capability for the entire agribusiness value chain.

Practical implications - Upstream firms should adopt new management techniques and tools, efficiently using their resources, while downstream firms should absorb and transform new technologies into products and processes.

Social implications - The authors suggest formulating public policies that propose the recombination of innovation capabilities to organize agribusiness firms and avoid commodity-oriented market dependence.

Originality/value - The literature on agribusiness explains innovation at the chain level, based primarily on scientific advancements rather than on innovation at the firm level. In this sense, this study provides empirical evidence that can help boost innovation in agribusiness firms.
\end{abstract}

Keywords Agribusiness, Innovation capabilities, Innovative performance, Value chain, Emerging economies, Brazil

Paper type Research paper

(C) Ricardo Machado Leo, Guilherme Freitas Camboim, Ariane Mello Silva Avila, Fernanda Maciel Reichert and Paulo Antônio Zawislak. Published in RAUSP Management Journal. Published by Emerald Publishing Limited. This article is published under the Creative Commons Attribution (CC BY 4.0) licence. Anyone may reproduce, distribute, translate and create derivative works of this article (for both commercial and non-commercial purposes), subject to full attribution to the original publication and authors. The full terms of this licence maybe seen at http://creativecommons.org/ licences/by/4.0/legalcode

This work was supported by the Brazilian National Council for Scientific and Technological Development (CNPq); the Coordination for the Improvement of Higher Education Personnel (CAPES); and the State of Rio Grande do Sul Research Foundation (FAPERGS).

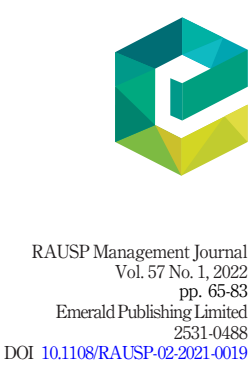


RAUSP

57,1

66

\section{Introduction}

The advances in science, technology and digital convergence are proposing different opportunities for agribusiness. New technologies are fusing physical, digital and biological domains, redefining innovation for the sector and challenging the firms, as well as their value chains, to rethink how to perform the whole activity. More than simple buy-and-sell relations through which firms transact products under changeless technological interfaces, value chains must possess innovative behavior.

In developed agribusiness value chains, the pace of the technological revolution is shifting the production from homogeneous commodities toward value-added products, increasing the demand for quality through higher standards (Kalaitzandonakes, Carayannis, Grigoroudis, \& Rozakis, 2018). Accordingly, agriculture value chains are not only applying new technology and creating new products but also innovating through new services and new modes of organization (Dias, Rodrigues, \& Ferreira, 2019).

Conversely, underdeveloped agribusiness value chains are still focused on producing commodities, which are volume-based, naturally stable and demand naturally fewer innovation efforts. Moreover, in this kind of value chain, firms have a strong dependence on the price mechanism and have significant levels of technological delay. Consequently, these value chains are characterized chiefly by pure transactional relations, undermining the role of firms as potential agents of innovation (Adenle, Manning, \& Azadi, 2017).

Considering this dichotomous behavior, it is necessary an approach that allows the understanding not only of the role of firms in shaping the different technological and transactional paths of agribusiness but also how they change them to innovate. Unfortunately, the traditional approaches embedded in Neoclassical and Transactional Cost Economics do not fulfill this need (Zylbersztajn, 2017; Mac Clay \& Feeny, 2018).

Facing this gap, the literature on agribusiness has recently tried to understand innovation but conducting its analysis at the chain level (Donovan, Franzel, Cunha, Gyau, \& Mithöfer, 2015; Santoro, Vrontis, \& Pastore, 2017; Mugwagwa, Bijman, \& Trienekens, 2020), whereas technological change occurs within the firms (Nelson, Dosi, Helfat, \& Winter, 2018). By placing the focus on the firm (even if still within a chain), this new approach must be able to capture the heterogeneity of behaviors and, therefore, the complex evolutionary processes resulting therefrom (Boehlje, Roucan-Kane, \& Bröring, 2011; Petry, Sebastião, Martins, \& de Azevedo Barros, 2019; Nelson et al., 2018).

Evolutionary Economics has sought to understand the innovative behavior of firms through their capabilities (Nelson et al., 2018). Capabilities have been approached from the technological to the dynamic perspective and can be defined as the firm's ability to perform an innovation (Zawislak, Cherubini Alves, Tello-Gamarra, Barbieux, \& Reichert, 2012). In fact, the capabilities approach aims to understand the set of knowledge, technologies, skills, resources and routines that a firm needs to master, not only to ensure minimum efficiency within a given technological standard but also to keep up with new trends, advances in science and the market (Teece, 2014; Carayannis, Grigoroudis, Del Giudice, Della Peruta, \& Sindakis, 2017).

In this sense, what are the innovation capabilities of firms in agribusiness value chains? How do innovation capabilities combine themselves? Does value chain position (link) influence firm performance? To answer these research questions, this paper aims to identify the winning combination of innovation capabilities for selected Brazilian agribusiness firms along different value chain links.

We propose this objective to argue that a firm's innovation capabilities shape the value chains' innovative behavior. First, we applied the innovation capabilities model proposed by 
Zawislak et al. (2012) on a sample of 300 Brazilian agribusiness firms. Then, we performed a multi-regression to analyze the configuration of innovation capabilities and their impact on the firms' innovative performance (IP).

Our study's originality consists of offering a step forward in agribusiness by understanding innovation capabilities at the firm level as the critical element to perceiving innovation dynamics at the chain level. Also, this study is justified because innovation capabilities are an underexplored concept in the sector and the studies that have so far tried to explore this area have analyzed only one link in the agribusiness value chain (Oliveira, Ruffoni, Maçada, \& Padula, 2019) instead of capturing innovation across different links, as we hereby propose.

\section{The emergence of agribusiness value chains}

The first studies observing the challenges in agribusiness came up in the middle of the twentieth century when economists approached agriculture production through the lens of market pricing, viewing the agricultural sector as an interdependent unit. In this sense, traditional agribusiness value chains, for the most part, are underdeveloped value chains formed by companies that tend to be homogeneous and focus on lower costs, as well as higher production volume (Zylbersztajn, 2017). This chain extends the agricultural activity to attract a more significant number of firms working in different links.

Pham and Stack (2018) defined six links in the agribusiness chain: input suppliers, farmers, traders, processors, retailers and consumers. Figure 1 illustrates the string of markets that form the agriculture value chain.

Briefly, the value chain is a set of technological interfaces interconnected by transactions, where one stage of the activity ends exactly where another begins (Williamson, 1985). On the one hand, the technology developed by the selling agent serves as complementarity of knowledge so that the buying agent is able to overcome its inherent limitations of knowledge imposed by limited rationality. On the other hand, the established transaction serves as a reward for the agent who sells the technology to maintain the pursuit of technological efforts.

Thus, the boundedness of knowledge draws the necessary combination of transactions with other agents, defining the technological content of the system and bridging two or more economic agents through transactions (Alves, Barbieux, Reichert, Tello-Gamarra, \& Zawislak, 2017). To go beyond these limitations, economic agents need to use new and improved technological efforts aiming to be recognized by the market, thereby attracting more transactions, expanding their limits and developing their respective value chains.

\subsection{Innovation in agribusiness value chains}

The traditional literature on innovation has focused on technological innovation in manufacturing environments (Malerba \& McKelvey, 2020); however, the nature of agribusiness innovation differs from manufacturing industries (Triguero, Córcoles, \&

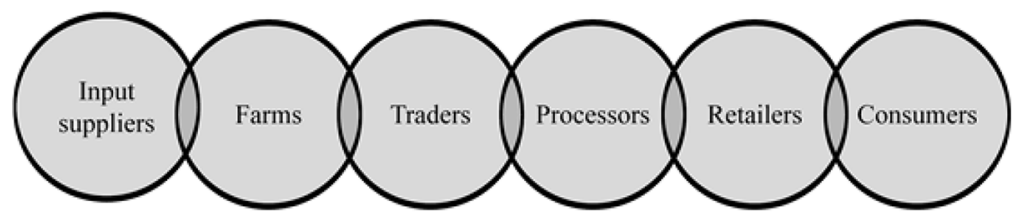

Source: Pham and Stack (2018)

Figure 1. Agriculture value chain 
RAUSP

57,1

68

Cuerva, 2013). Agribusiness deals with different forms of life rather than inert elements as manufacturing firms do. While inert products may be manufactured following strict and localized processes, agriproducts are dependent on geographically spread processes.

Consequently, most studies in agribusiness aim to explain innovation at the chain level (Boehlje et al., 2011). Following this context, the literature on innovation in agribusiness is split into two major streams to explain the outcomes of innovation: technology and transaction.

Regarding technology, areas such as entrepreneurship (Mirzaei, Micheels, \& Boecker, 2016), new product development (Santoro et al., 2017), digital farming, new technologies, applied technics, production and eco-efficiency (Cambra Baseca, Sendra, Lloret, \& Tomas, 2019) have been studied. As for transactions, the literature attempts to explain innovation at the chain level, including such issues as contracts, networking and logistics (Cantù et al., 2015; Cembalo, 2015).

Considering the scenario outlined above, the literature on innovation in agribusiness provides a broad approach to the phenomenon, where technology is something exogenous to the system. In this sense, transactions draw the technological limits of each link and, consequently, the role of the different actors in a chain at a given moment in time. However, this is not sufficient to understand innovation in a specific and dynamic way.

Following this argument, one needs to understand innovation at the firm level before rising to the chain level. In fact, we argue that the different technological content along each link demands different combinations of innovation capabilities to perform better economically and technologically, as well as to complement the following link in the chain.

\section{Firms and innovation capabilities in agribusiness}

Innovation capability means the capacity to innovate and consequently, to guarantee a firm's competitive advantage and sustainable success (Le \& Lei, 2018). Specifically, innovation capability is a meta-capability (Collis, 1994) developed under diverse topics such as human resources (Penrose, 1959), specific skills (Richardson, 1972), absorptive capacity (Cohen \& Levinthal, 1990), technological capabilities (Lall, 1992) and innovative capabilities (Bell \& Figueiredo, 2012).

Thus, innovation capability ranges from the technological dimension that embraces product development and the operation of the respective processes to the non-technological dimension that deals with the managerial and transactional routines necessary to assure profitable sales. For Zawislak et al. (2012), the firm's innovation capability is a meta-concept, covering four singular capabilities that, when effectively combined, promote innovation and competitive advantage.

The model has its roots in the Neo-Schumpeterian theoretical approach, attaching each type of innovation to its respective capability. The model (Figure 2) shows that any firm has

Figure 2.

Innovation capabilities of the firm

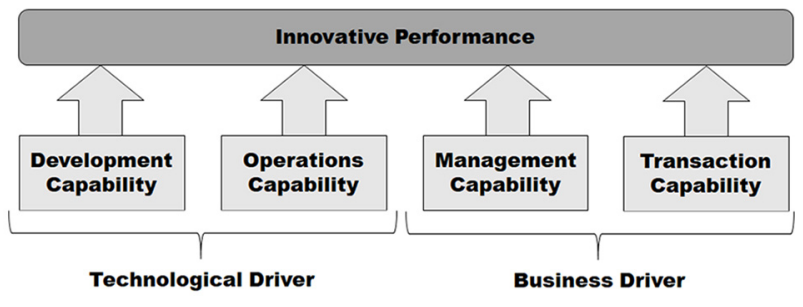

Source: Retrieved from Zawislak et al. (2012) 
two major dimensions: technological (development and operations capabilities) and business (management and transaction capabilities).

Several studies have covered the importance of innovation capabilities and most of them have shown how important they are for firm performance. Dadfar et al. (2013) state that superior innovation capabilities tend to implement and develop a new product. Vicente, Abrantes and Teixeira (2015) argue similarly that innovation capabilities enhance new product development through the combination of innovation behavior, strategic capability and internal technological process. Thus:

Innovation capabilities in agribusiness

H1. Innovation capabilities have a positive effect on the IP of agribusiness firms.

The development capability is the root of a firm's long-term competitive advantage because it consists of the driving force of a firm's innovation (Saranga, George, Beine, \& Arnold, 2018). The development capability allows the firm to deal strategically with technology, creating new methods, processes, techniques and, mainly, new products (Zhou \& Wu, 2010; Gurtner \& Reinhardt, 2016).

Specifically in agribusiness, development capability has been associated with issues such as patenting in food technology and non-food technological firms (Alfranca, Rama, \& von Tunzelmann, 2003) According to these authors, agribusiness firms should strategically combine different types of technological capabilities in a variety of industrial situations, to achieve technological diversification. Thus:

H1a. Development capability has a positive effect on the IP of agribusiness firms.

Operation capabilities are vital for enterprises' daily operations and they reflect on the effectiveness of business operations (Jantunen, Tarkiainen, Chari, \& Oghazi, 2018). The operation capability consists of how the firm uses its previously developed knowledge, abilities, routines and technical systems to efficiently operate technology to produce tradable goods and services (Zawislak et al., 2012).

These capabilities derive from establishing competitive priorities aiming to take advantage of lower costs, higher quality, delivery time, flexibility, workflow, etc (Sansone, Hilletofth, \& Eriksson, 2017). As a consequence, operation capabilities' main objective is to reduce production, manufacturing and transport costs to increase profit margins and produce high-quality products at the lowest operating cost (Prajogo, Toy, Bhattacharya, Oke, \& Cheng, 2018). Thus:

$H 1 b$. Operations capabilities have a positive effect on the IP of agribusiness firms.

Management capability arises from the transactional costs that the firm assumes when it proposes to fill a market gap (Williamson, 1985). This aspect brings together the role of a coordinator and entrepreneur, seeking to allocate the production factors optimally, minimizing the transactional costs and uncertainty (Coase, 1937; Simon, 1945). Consequently, management capability is the ability to integrate and combine productive resources to achieve higher levels of resource utilization and the ability to assume risk and anticipate shortages (Zawislak et al., 2012; Pufal et al., 2014; Teece, 2019).

Thus, management capability can provide clear directions and goals (Tseng \& Lee, 2014). Furthermore, by achieving higher levels of management capability, the firm will be able to perform management and new processes that produce changes in the firm's strategy, structure, administrative processes and systems (Damanpour \& Aravind, 2011). Thus:

H1c. Management capability has a positive effect on the IP of agribusiness firms. 
RAUSP

57,1
Finally, the last capability approached in the model is the transactional capability (Langlois and Foss, 1999; Williamson, 1999; Tello-Gamarra, Hernani-Merino, \& Límaco-Mamani, 2017). This capability is the effort to sell the technological solution developed and operationalized in the technological capability and operation capability, respectively (Zawislak et al., 2012). In this sense, the transactional capability allows the firm to learn how to contract to reduce its marketing, bargaining and delivering costs (Tello-Gamarra \& Zawislak, 2013).

In addition, Dentoni, English and Schwarz (2014) highlight the importance of marketing capabilities in the agricultural context as key drivers of a firm's market orientation. They argue that the market has shifted from producers supplying whatever is on offer to a scenario where they listen to the customers' demands and tailor their production to meet these demands. Thus:

\section{H1d. Transaction capability has a positive effect on the IP of agribusiness firms.}

The model presented expresses how each capability contributes to the IP of a firm. Every firm has a combination of all four capabilities and none of them are null. The chosen model presents a balanced view, linking the technology driver (development and operations capabilities) with the business driver (management and transaction capabilities) of the firm (Alves et al., 2017). Recently, the same model has also been applied in different studies showing its replicability (Reichert, Zawislak, \& Arundel, 2016; Heredia, Flores, Heredia, Arango, \& Medina, 2019; Oliveira et al., 2019).

Using the same model to analyze food companies, Oliveira et al. (2019) confirmed that only the development capability and transaction capability substantially impact firms' IP. However, as initially argued, there are different firm behaviors in agribusiness value chains, evidencing firm heterogeneity and the need for different and creative recombination of resources and skills to develop superior products and to introduce them quickly into the market (Adenle et al., 2017; Dias et al., 2019).

This heterogeneity suggests that different knowledge, skills and resources are complementary through the different technological interfaces established between the different economic agents (Lançon, Temple, \& Biénabe, 2017). Consequently, different combinations of innovation capabilities are needed to ensure the technological and transaction dynamics along with each value chain link. Overall, we formalize this argument in the following hypothesis:

\section{H2. Chain Position has a positive effect on the IP of agribusiness firms.}

The lack of studies that properly capture innovation capabilities along the agribusiness value chain, as well as the evidence which indicates that innovation capabilities arrange themselves according to each chain link, supports the need to fill this literature gap. This is reinforced by the entirely different nature of activity found in agribusiness (the biological nature present in its products), suggesting that firms in agribusiness also have a particular set of innovation capabilities.

\section{Research method}

\subsection{Data}

To identify the winning combination of innovation capabilities for selected Brazilian agribusiness firms along with different value chain links, we used a database from an innovation survey conducted by the Innovation Research Center, which evaluated 22 manufacturing sectors across Brazilian industries. Brazilian manufacturing firms are 
generally from low-tech intensity sectors: approximately $90 \%$ of the sample firms are characterized as small and $89 \%$ are family-managed and $83 \%$ are focused on operations and cost-based strategies (Alves et al., 2017).

This database consisted of 1,543 firms that answered the questionnaire; for reasons such as incomplete answers, 1,331 questionnaires were considered valid. From these 1,331 manufacturing firms listed on the database, we selected only agribusiness firms and divided them into upstream (i.e. agrochemicals, agricultural machinery, paper and pulp, wood) and downstream (i.e. beverages, food, tobacco), resulting in a total of 300 firms. As Table 1 shows, the sample was composed of $54.4 \%$ upstream firms and $45.6 \%$ downstream firms.

We divided the sample into upstream and downstream firms due to the current literature that seeks to classify firms according to their contribution to the production process. While upstream firms deal with extracting raw materials, downstream firms are concerned with material processing, transforming them into a finished product for the final consumer (Swaray \& Salisu, 2018).

The survey instrument was a questionnaire written in Portuguese and divided into two blocks, using a five-point interval scale. In the first block, there were four parts, each related to one of the four capabilities: management (MC), transaction (TC), operation (OC) and development capability (DC). This first block aimed to capture the existence of routines and specificities of each firm's capabilities by using an interval scale (one to five) to measure the degree of agreement. The second block measured IP using the same interval scale to check the degree to which firms agreed to increase their economic indicators on the previous year.

Professional interviewers collected data through computer-assisted telephone interviews with the firm's owner, president, directors or top managers. Appendix shows the questions used on the final survey and the number of scale variables in each construct.

\subsection{Measures}

The measurement scale developed for this study follows the discussions and measures of relevant constructs in the literature on innovation capabilities. As previously mentioned, we used the innovation capabilities model developed by Zawislak et al. (2012, 2013, 2014); based on this model, respondents answered questions on all subjective measures (i.e. innovation capabilities and IP) with a Likert-scale ranging from 1 (strongly disagree) to 5 (strongly agree).

4.2.1 Dependent variable. Assuming that innovation is the result of several integrated routines and activities that positively affect firm performance, we considered three leading economic indicators to measure the "innovative performance" of firms. The literature highlights that performance has been commonly assessed through financial measures, internal efficiency or market performance (Schoenecker and Swanson, 2002; Coombs and

\begin{tabular}{|c|c|c|c|c|}
\hline Chain position & Sector & Sample & $(\%)$ & \\
\hline & Total & 300 & 100 & \\
\hline \multirow[t]{4}{*}{ Upstream } & Agricultural machinery & 62 & 20.7 & \\
\hline & Agrochemicals & 17 & 5.7 & \\
\hline & Paper and Pulp & 32 & 10.7 & \\
\hline & Wood & 52 & 17.3 & \\
\hline \multirow[t]{3}{*}{ Downstream } & Beverages & 10 & 3.3 & Table 1. \\
\hline & Food & 120 & 40.0 & Selected agribusiness \\
\hline & Tobacco & 7 & 2.3 & firms \\
\hline
\end{tabular}


RAUSP

57,1

Bierly, 2006). In this study, IP is a construct composed of variables that reflect positive growth in terms of revenue, profit and market share (Appendix).

4.2.2 Independent variables. Considering that every firm has four complementary innovation capabilities, namely, DC, OC, MC and TC, it is necessary to capture which combination enables the creation of competitive advantages (Zawislak et al., 2012).

These capabilities measure the degree of existence of specific routines relevant to each function performed by the firm. In this study, each innovation capability construct is composed of a set of variables that reflect how firms develop products, manage their operations, coordinate and arrange their activities and reduce their transaction costs. It means that the firms will be more prone to innovate depending on the level of their innovation capabilities. In addition, we created a dummy variable $(0=$ upstream; $1=$ downstream), which reflects the firm's position in the value chain (CP).

4.2.3 Control variable. To rule out confounding explanations, this study included the size of the selected firms as a control variable. Firm size was controlled because larger companies may have more significant resources to generate high performance. Size was measured considering the firm's gross revenue grouped in five categories following the Brazilian Development Bank (BNDES) classification.

\section{Statistical methods and results}

Table 2 presents the descriptive statistics for the two groups according to their position in the value chain (CP variable). The mean values show that agribusiness firms mainly focus on operations capability to carry out their activities independently of their position in the value chain.

Then, firms put their efforts into activities that refer to $\mathrm{MC}$ and $\mathrm{DC}$, with a slight difference depending on their position in the value chain. Conversely, the TC has the lowest mean in both groups, indicating these firms' inability to deal with the market. The ANOVA test also confirmed that their means are significantly different.

To achieve our objective, we performed a factorial analysis to form the constructs and a multi-regression analysis to identify the existing innovation capability (DC, OC, MC and TC) combinations in agribusiness and how they impact the IP.

We selected the same 20 variables from Alves et al. (2017) for the factorial analysis, which were reduced to four constructs corresponding with each innovation capability through the Varimax rotation technique. Data adequacy was analyzed using the KaiserMeyer-Olkin measurement of sampling adequacy (KMO) and Bartlett's sphericity tests, which produced satisfactory results (Hair, Celsi, Ortinau, \& Bush, 2010). The variables loaded onto four factors with loadings $\geq 0.50$. The same was carried out to form the IP construct, in which variables were grouped in one factor.

After the factorial analysis, we created four different models through multi-regression to test the relationship among the innovation capabilities, the firms' position in the value chain and their IP. In Models I and II, we split the sample into two groups to test the coefficients of

Table 2.

Descriptive results of agribusiness firms" innovation capabilities

$$
\text { Upstream (U) }
$$

Variable Mean SD Minimum Maximum Mean SD Minimum Maximum Mean SD Minimum Maximum

\begin{tabular}{|c|c|c|c|c|c|c|c|c|c|c|c|c|}
\hline $\mathrm{DC}$ & 3.68 & 0.76 & 1.17 & 5.00 & 3.82 & 0.76 & 1.33 & 5.00 & 3.75 & 0.76 & 1.17 & 5.00 \\
\hline $\mathrm{OC}$ & 3.94 & 0.60 & 2.40 & 5.00 & 4.17 & 0.51 & 2.80 & 5.00 & 4.04 & 0.57 & 2.40 & 5.00 \\
\hline $\mathrm{MC}$ & 3.64 & 0.70 & 1.60 & 5.00 & 3.87 & 0.65 & 2.20 & 5.00 & 3.75 & 0.69 & 1.60 & 5.00 \\
\hline $\mathrm{TC}$ & 3.43 & 0.75 & 1.00 & 5.00 & 3.60 & 0.71 & 2.00 & 4.75 & 3.51 & 0.74 & 1,00 & 5.00 \\
\hline
\end{tabular}


each capability and their significance for upstream and downstream firms individually. In Models III and IV, we performed a multi-regression for the entire sample, but in Model IV, a dummy variable chain position was also included. Finally, in Model V, we introduced the control variable to measure significant differences among companies considering their size.

In Table 3, the results from the multi-regression analysis show that all four models were significant at p-level $<0.001$ and had a power of explanation $\left(R^{2}\right)$ above $22 \%$, which, according to Hair et al. (2010), is acceptable to social sciences. Furthermore, analyzing the $R^{2}$ adjusted, it is possible to confirm that there was no variable excess in the models because there was but a slight difference between $R^{2}$ and $R^{2}$ adjusted.

In all models, DC, MC and TC were significant to the IP $(p<0.001)$, while OC was not significant $(\phi>0.1)$. Models I and IV found the highest coefficients within the business driver capabilities: TC had the greatest impact on IP, followed by MC and DC. There was a slight difference in model II, where MC assumed a less important role than DC and TC. Interestingly, the capabilities coefficient scores for upstream firms (Model I) were higher than those for downstream firms (Model II).

Furthermore, by adding the CP variable in the equation (Model IV), the $R^{2}$ increased compared to Model III, which considers both up and downstream firms. Thus, despite being the lowest coefficient value, the $\mathrm{CP}$ had a significant impact $(p<0.05)$ on IP.

From Table 2, the models for upstream firms [Equation (1)], downstream firms [Equation (2)], the agribusiness value chain [Equation (3) without $\mathrm{CP}$ and Equation (4) including $\mathrm{CP}$ ] and the agribusiness value chain and the size of companies [Equation (5) including S] could be summarized in five equations:

$$
\begin{gathered}
\mathrm{IP}=0.333 \mathrm{TC}+0.322 \mathrm{MC}+0.247 \mathrm{DC}+\mathrm{e} \\
\mathrm{IP}=0.162+0.265 \mathrm{TC}+0.65 \mathrm{MC}+0.218 \mathrm{DC}+\mathrm{e} \\
\mathrm{IP}=0.026+.306 \mathrm{TC}+0.309 \mathrm{MC}+0.238 \mathrm{DC}+\mathrm{e} \\
\mathrm{IP}=0.302 \mathrm{TC}+0.295 \mathrm{MC}+0.234 \mathrm{DC}+0.240 \mathrm{CP}+\mathrm{e} \\
\mathrm{IP}=0.213 \mathrm{DC}+0.025 \mathrm{OC}+0.274 \mathrm{MC}+0.275 \mathrm{TC}+0.199 \mathrm{CP}+0.166 \mathrm{~S}+\mathrm{e}
\end{gathered}
$$

These results validate previous investigations showing that different firms achieve IP through different capability arrangements (Reichert et al., 2016; Alves et al., 2017) and confirm that the innovation capabilities model is also suitable for analyzing agribusiness firms in terms of their IP.

It is also important to note that equation (4) proves that the position in the value chain does matter for innovation and highlights the winning combination of innovation capabilities in agribusiness. The following section brings further discussion on these results.

\section{Discussion}

According to our results, innovation capabilities positively impact agribusiness firms, evidencing that firms along an agribusiness value chain have different knowledge, routine 
RAUSP

57,1

74

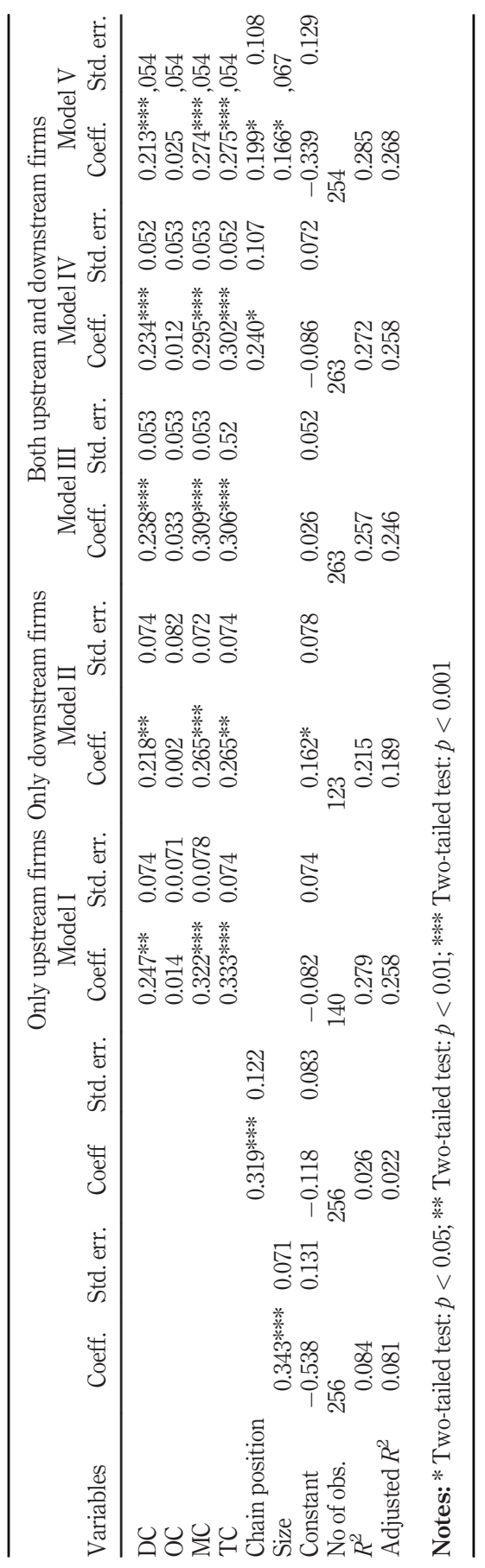

Table 3.

Regression analysis of innovation capabilities models 
and resource arrangements that will permit them to perform innovations. Therefore, our central hypothesis (H1) was partially confirmed.

Among the four innovation capabilities, our regression models suggest that the operation capability has no significant effect on the IP of the firm, invalidating our $H 1 b$ hypothesis and confirming the findings by Alves et al. (2017), who argued that the operation capability consists of a capability mastered by everyone. As a consequence, operation capabilities can be classified as ordinary capabilities.

Ordinary capabilities have been described as zero-level capability (Helfat \& Winter, 2011; Schilke, 2014) and thought of as "doing things right" in the core business functions (Teece, 2014). However, it is essential to highlight that the operational capability is intertwined with the technological regime of a given industrial matrix. Depending on the asset specificity of this industrial matrix, the operations will be more or less critical for IP.

In such a case, the best performing firms surpass operations as the primary capability and focus on development, management and transaction capabilities to foster innovation. In fact, that is what seems to make a difference in a commodity-oriented industrial matrix. Our regression models generally show that agribusiness firms must focus on enhancing business-driven capabilities to achieve higher IP, confirming other studies' findings (Caiazza et al., 2016).

The transaction capability has the most significant impact on IP for all models, validating our $H 1 d$ hypothesis. This means that the agribusiness firms must reduce their marketing, bargaining and delivering costs and seize new market opportunities to capture higher value from transactions (Dentoni et al., 2014). As stated before, even looking at the firm level, the boundedness of firms points at the transaction - and thus at the chain level for better performance. To do this, these firms should improve their relationship with both suppliers and clients by establishing better contracts, getting closer to the end-costumer and investing in marketing activities to enhance their transaction capability.

The second capability that impacts innovative behavior most is management capability, meaning that our H1c hypothesis is also validated. Management capability refers to how firms coordinate and integrate their activities to guarantee efficiency throughout the processes (Zawislak et al., 2012). Consequently, firms should enhance the management techniques and implement suitable strategies to achieve the best possible business coordination or even design and implement new business models (Helfat \& Martin, 2015).

Last but not least, development capability also has a positive impact on agribusiness firms, validating our $H 1 a$ hypothesis. Considering development capability as significant for agribusiness firms means that these firms should make purposeful and conscious investments in learning and the accumulation of experience (Whitfield, Staritz, Melese, \& Azizi, 2020). This learning accumulation permits firms to develop new and improved products to achieve more complex markets compared to commodity markets.

Considering that transactional, management and development capabilities are responsible for agribusiness firms' superior performance, it is possible to infer that these capabilities are dynamic. Dynamic capabilities enable firms to upgrade other capabilities and direct them toward high-payoff endeavors, which requires developing and coordinating resources to address and even shape changes in the marketplace (Teece, 2018).

Nevertheless, according to Reichert et al. (2016):

- there must be a combination of capabilities to achieve higher IP and

- the improvement of transaction capability alone is not sufficient.

Our models suggest precisely that, providing two combination patterns. The first is for upstream firms and the value chain, which must focus on combining management and 
RAUSP

57,1

development, respectively, with transactions (Model I, III, IV). The second pattern is for downstream firms, which must focus on the combination of development and management, respectively, with transactions (Model II).

Considering the first pattern specifically, Models I, III and IV indicate that the second capability to be combined with transactions is management capability. By enhancing management capabilities, agribusinesses firms should constantly improve their organizational structures and mechanisms to adapt to economic dynamics.

However, they also need to transform technological development into coherent arrangements of operations and transactions by enhancing their management capability. In this context, development capability is, somehow, a "secondary level," right after "primary" business-oriented concerns. Agribusiness deals with life-embedded products and this characteristic restrain the development of new products imposing a slower pace than other economic activities (Cantù et al., 2015). This condition raises the required level of knowledge by agribusiness economic agents and influences how the firm position in the value chain affects knowledge generation for innovation (Model IV).

In this case, the focus on development capability should be a long-term concern in agribusiness firms to develop new products and add value to them. This capability, combined with transaction and management capabilities, enables a new dynamic among the different links of the value chain (Fritz \& Schiefer, 2008).

Therefore, contradicting Alves et al. (2017), transactions are more important than management and development capabilities for agribusiness firms because value chains assume a significant role in coordinating economic activity. As a consequence, unlike manufacturing industries, where the need for internal coordination places the management capability as the most important, in agribusiness, the transaction capability is the key to IP, as the sector depends on value chains to achieve IP.

Finally, our results (Model IV and V) indicate that the chain-link position provides a different set of innovation capability combinations, validating our $H 2$ hypothesis. Given a firm position on the value chain, a specific innovation capabilities arrangement to each link is necessary to achieve IP. Not surprisingly, this result shows that agribusiness firms possess different innovative behaviors instead of being homogeneous economic actors or transactional units, as previously mentioned by the traditional literature.

\section{Final comments}

This paper focused on identifying the winning combination of innovation capabilities for selected Brazilian agribusiness firms along with different value chain links. We argue that firms are essential for the innovation process and outcomes of agribusiness value chains. In this sense, this study offers several contributions to understand innovation in agribusiness and provides managerial insights related to the importance of the firm's position along the value chain.

\subsection{Implications for theory and practice}

The gap this paper addresses is to understand how innovation in the value chain finds its pillars in the innovation capabilities of agribusiness firms, considering that few studies deal with the innovation capabilities in agribusiness. However, we furthered the idea by understanding innovation capabilities at the firm level as the key element to perceiving innovation dynamics at the chain level.

Our results confirmed this assumption. Agribusiness firms have an essential role in the innovation process, requiring a specific combination of capabilities for different links on the value chain. For upstream firms, transaction and management capabilities are the most 
important to achieve IP, as these firms are further from the end consumers. For downstream firms, closer to the end consumers, transaction and development capabilities support IP. These two patterns of innovation capability combinations shed light on the importance of the link position to establishing the innovation capability combinations, confirming that the firm is the main innovation protagonist, although still chain-dependent when combining capabilities.

Therefore, our findings suggest that the business driver is significant for agribusiness firms, proposing that they find new ways to transact with the market and to have more efficient coordination mechanisms to deal with competitive environments such as global commodity markets.

Contrary to the winning combination model, our results show that Brazilian agribusiness firms focus primarily on operations instead of other capabilities. However, as operations have no significant impact on IP and can be considered a capability mastered by everyone, this option goes against competitiveness. Therefore, agribusiness firms from a commodity value chain must recombine their capabilities to emphasize the transaction, management and development capabilities, according to the firm's position along the value chain.

As to the importance of the firm's position along the value chain, this study provides managerial evidence for upstream and downstream firms. Upstream firms should focus their efforts on adopting new management techniques and tools, making efficient use of their resources and understanding the strategies of new business models. The primary goal is to ensure the functioning and continuous search for internal efficiency.

Downstream firms should focus their efforts on absorbing and transforming new technologies into products and processes that meet industry needs. In both cases, there is a need to understand their performance with the external public. Agribusiness firms should focus on relationships with suppliers and customers, as well as commercial strategies for brand and reputation development.

For policymakers, we suggest formulating public policies that propose the recombination of innovation capabilities to organize agribusiness firms and avoid commodity-oriented market dependence, considering the existence of niche markets.

In sum, the Brazilian agribusiness sector can be more innovative, focusing on transaction capabilities. It means that these firms need to improve their relationship with customers to minimize the transaction costs inherent in any market.

\subsection{Limitations and further research}

As with any study, the present one has limitations, many of which highlight exciting opportunities for future research. First, we only analyzed the input suppliers and industry of the overall agribusiness value chain. It is noteworthy that other links such as traders and retailers, deserve attention to find the innovation capability for the entire agribusiness value chain. Second, we analyzed Brazilian agribusinesses; therefore, it is impossible to generalize the results for all emerging countries because each economy may have its own particularities.

Also, for future research, we believe that researchers must pay attention to the farming link, especially in commodity-based markets where every firm along the chain must be coordinated to support the chain"s efficiency. Farming is the unit along the chain that deals with the distinctive feature of agribusiness, e.g. life, in a most proficuous way. It is on the farm that life grows before becoming a manufactured product. However, it is precisely this farming link that lacks innovation capability studies, leaving a gap to be filled.

Given our limitations, we recommend considering other links in the agribusiness chain to widen the analysis in future studies. It is necessary to analyze the interaction among firms 
RAUSP

57,1

from each link to understand how innovation occurs along the agribusiness chain. Besides that, it would be interesting to use the data to run a fuzzy-set analysis through the Qualitative Comparative Analysis (QCA) method to see which innovation capacities are needed, which are sufficient and which should be absent for enhancing innovation performance.

\section{8}

\section{References}

Adenle, A. A., Manning, L., \& Azadi, H. (2017). Agribusiness innovation: A pathway to sustainable economic growth in africa. Trends in Food Science \& Technology, 59, 88-104. doi: https://doi.org/ 10.1016/j.tifs.2016.11.008.

Alfranca, O., Rama, R., \& von Tunzelmann, N. (2003). Technological capabilities in multinational agribusiness. International Journal of Agricultural Resources, Governance and Ecology, 2(3/4), 383-398. doi: https://doi.org/10.1504/IJARGE.2003.003978.

Alves, A. C., Barbieux, D., Reichert, F. M., Tello-Gamarra, J., \& Zawislak, P. A. (2017). Innovation and dynamic capabilities of the firm: Defining an assessment model. Revista de Administração de Empresas, 57(3), 232-244. doi: https://doi.org/10.1590/s0034-759020170304.

Bell, M., \& Figueiredo, P. N. (2012). Innovation capability building and learning mechanisms in latecomer firms: Recent empirical contributions and implications for research. Canadian Journal of Development Studies/Revue Canadienne D'études du Développement, 33(1), 14-40. doi: https:// doi.org/10.1080/02255189.2012.677168.

Boehlje, M., Roucan-Kane, M., \& Bröring, S. (2011). Future agribusiness challenges: Strategic uncertainty, innovation and structural change. International Food and Agribusiness Management Review, 14(5), 53-82.

Cambra Baseca, C., Sendra, S., Lloret, J., \& Tomas, J. (2019). A smart decision system for digital farming. Agronomy, 9(5), 216. doi: https://doi.org/10.3390/agronomy9050216.

Cantù, C., Corsaro, D., Tunisini, A., Dagnino, G. B., Levanti, G., Minà, A., \& Picone, P. M. (2015). Interorganizational network and innovation: A bibliometric study and proposed research agenda. Journal of Business \& Industrial Marketing, 30(3/4), 354-377.

Carayannis, E. G., Grigoroudis, E., Del Giudice, M., Della Peruta, M. R., \& Sindakis, S. (2017). An exploration of contemporary organizational artifacts and routines in a sustainable excellence context. Journal of Knowledge Management, 21(1), 35-56. doi: https://doi.org/10.1108/JKM-102015-0366.

Cembalo, L. (2015). Innovation and valorization in supply chain network. Agricultural and Food Economics, 3(1), 1-4. doi: https://doi.org/10.1186/s40100-014-0028-8.

Coase, R.H. (1937). The nature of the firm. Economica, 4(16), 386-405.

Cohen, W. M., \& Levinthal, D. A. (1990). Absorptive capacity: A new perspective on learning and innovation. Administrative Science Quarterly, 35(1), 128-152. doi: https://doi.org/10.2307/2393553.

Collis, D. J. (1994). Research note: How valuable are organizational capabilities?? Strategic Management Journal, 15(S1), 143-152. doi: https://doi.org/10.1002/smj.4250150910.

Coombs, J.E., \& Bierly III, P.E. (2006). Measuring technological capability and performance. R\&D Management, 36(4), 421-438.

Caiazza, R., Volpe, T., Stanton, J. L., Griffith, C. J., De Mori, C., Batalha, M. O., \& Alfranca, O. (2016). A model for measuring technology capability in the agrifood industry companies. British Food Journal, 118(6), 1422-1461.

Dadfar, H., Dahlgaard, J.J., Brege, S. \& Alamirhoor, A. (2013). Linkage between organisational innovation capability, product platform development and performance: the case of pharmaceutical small and medium enterprises in Iran. Total Quality Management and Business Excellence, 24(7/8), 819-834. doi: https://doi.org/10.1108/JADEE-07-2013-0025. 
Damanpour, F., \& Aravind, D. (2011). Managerial innovation: Conceptions, processes, and antecedents. Management and Organization Review, 8(2), 423-454. doi: https://oi.org/10.1111/j.17408784.2011.00233.x.

Dentoni, D., English, F., \& Schwarz, D. (2014). The impact of public R\&D on marketing and supply chains on small farms? Market sensing capability: Evidence from the australian seafood industry. International Food and Agribusiness Management Review, 17(1), 37-58.

Dias, C. S., Rodrigues, R. G., \& Ferreira, J. J. (2019). What's new in the research on agricultural entrepreneurship? Journal of Rural Studies, 65, 99-115. doi: https://doi.org/10.1016/j. jrurstud.2018.11.003.

Donovan, J., Franzel, S., Cunha, M., Gyau, A., \& Mithöfer, D. (2015). Guides for value chain development: A comparative review. Journal of Agribusiness in Developing and Emerging Economies, 5(1), 2-23. doi: https://doi.org/10.1108/JADEE-07-2013-0025.

Fritz, M., \& Schiefer, G. (2008). Food chain management for sustainable food system development: A European research agenda. Agribusiness, 24(4), 440-452. doi: https://doi.org/10.1002/agr.20172.

Gurtner, S., \& Reinhardt, R. (2016). Ambidextrous idea generation - Antecedents and outcomes. Journal of Product Innovation Management, 33, 33-54.

Hair, J. F., Celsi, M., Ortinau, D. J., \& Bush, R. P. (2010). Essentials of marketing research, New York, NY: McGraw-Hill/Irwin.

Helfat, C. E., \& Winter, S. G. (2011). Untangling dynamic and operational capabilities: Strategy for the (N)ever-changing world. Strategic Management Journal, 32(11), 1243-1250. doi: https://doi.org/ 10.1002/smj.955.

Helfat, C. E., \& Martin, J. A. (2015). Dynamic managerial capabilities: Review and assessment of managerial impact on strategic change. Journal of Management, 41(5), 1281-1312. doi: https:// doi.org/10.1177/0149206314561301.

Heredia, J., Flores, A., Heredia, W., Arango, R., \& Medina, L. (2019). How innovation influences on export performance: A configuration approach for emerging economies. Journal of Technology Management \& Innovation, 14(4), 54-65. doi: https://doi.org/10.4067/S0718-27242019000400054.

Kalaitzandonakes, N., Carayannis, E. G., Grigoroudis, E., \& Rozakis, S. (2018). Innovation and technology transfer in agriculture: Concluding comments. In From agriscience to agribusiness (pp. 483-490). New York, NY: Springer.

Jantunen, A., Tarkiainen, A., Chari, S., \& Oghazi, P. (2018). Dynamic capabilities, operational changes, and performance outcomes in the media industry. Journal of Business Research, 89, 251-257. doi: https://doi.org/10.1016/j.jbusres.2018.01.037.

Lall, S. (1992). Technological capabilities and industrialization. World Development, 20(2), 165-186. doi: https://doi.org/10.1016/0305-750X(92)90097-F.

Lançon, F., Temple, L., \& Biénabe, E. (2017). The concept of filière or value chain: An analytical framework for development policies and strategies. Sustainable Development and Tropical AgriChains, 17-28.

Langlois, R.N. J., \& Foss, N.J. (1999). Capabilities and governance: the rebirth of production in the theory of economic organization. Kyklos, 52(2), 201-218.

Le, P. B., \& Lei, H. (2018). The effects of innovation speed and quality on differentiation and low-cost competitive advantage: The case of chinese firms. Chinese Management Studies, 12(2), 305-322. doi: https://doi.org/10.1108/CMS-10-2016-0195.

Mac Clay, P., \& Feeny, R. (2018). Analyzing agribusiness value chains: A literature review. International Food and Agribusiness Management Review, v. 22p. 31-46.

Malerba, F., \& McKelvey, M. (2020). Knowledge-intensive innovative entrepreneurship integrating schumpeter, evolutionary economics, and innovation systems. Small Business Economics, 54(2), 503-522. doi: https://doi.org/10.1007/s11187-018-0060-2. 
RAUSP

57,1

Mirzaei, O., Micheels, E. T., \& Boecker, A. (2016). Product and marketing innovation in farm-based businesses: The role of entrepreneurial orientation and market orientation. International Food and Agribusiness Management Review, 19, 99.

Mugwagwa, I., Bijman, J., \& Trienekens, J. (2020). Typology of contract farming arrangements: A transaction cost perspective. Agrekon, 59(2), 169-187. doi: https://doi.org/10.1080/ 03031853.2020.1731561.

Nelson, R. R., Dosi, G., Helfat, C. E., \& Winter, S. G. (2018). Modern evolutionary economics: an overview, Cambridge: Cambridge University Press.

Oliveira, C. A. O., Ruffoni, E. P., Maçada, A. C. G., \& Padula, Â. D. (2019). Innovation capabilities in the food processing industry in Brazil. British Food Journal, 121(11), 2901-2918. doi: https://doi.org/ 10.1108/BFJ-10-2018-0647.

Prajogo, D., Toy, J., Bhattacharya, A., Oke, A., \& Cheng, T. C. E. (2018). The relationships between information management, process management and operational performance: Internal and external contexts. International Journal of Production Economics, 199, 95-103. doi: https://doi. org/10.1016/j.ijpe.2018.02.019.

Penrose, E. (1959). The theory of the growth of the firm, New York, NY: John Wiley \& Sons.

Petry, J. F., Sebastião, S. A., Martins, E. G., \& de Azevedo Barros, P. B. (2019). Innovation and the diffusion of technology in agriculture in floodplains in the state of Amazonas. Revista de Administração Contemporânea, 23(5), 619-635. doi: https://doi.org/10.1590/19827849rac2019190024.

Pham, X., \& Stack, M. (2018). How data analytics is transforming agriculture. Business Horizons, 61(1), 125-133. doi: https://doi.org/10.1016/j.bushor.2017.09.011.

Puful, N.A., Zawislak, P.A., Alves, A.C., \& Gamarra, J.E.T. (2014). Management capability and the paradox of the organized firm. Strategic Management Quarterly, 2, 47-69.

Reichert, F. M., Zawislak, P. A., \& Arundel, A. (2016). Exploring innovation success recipes in lowtechnology firms using fuzzy-set QCA. Journal of Business Research, 69(11), 5437-5441. doi: https://doi.org/10.1016/j.jbusres.2016.04.151.

Richardson, G. B. (1972). The organisation of industry. The Economic Journal, 82(327), 883-896. doi: https://doi.org/10.2307/2230256.

Sansone, C., Hilletofth, P., \& Eriksson, D. (2017). Critical operations capabilities for competitive manufacturing: A systematic review. Industrial Management \& Data Systems, 117(5), 801-837. doi: https://doi.org/10.1108/IMDS-02-2016-0066.

Santoro, G., Vrontis, D., \& Pastore, A. (2017). External knowledge sourcing and new product development: Evidence from the italian food and beverage industry. British Food Journal, 119(11), 2373-2387. doi: https://doi.org/10.1108/BFJ-02-2017-0120.

Saranga, H., George, R., Beine, J., \& Arnold, U. (2018). Resource configurations, product development capability, and competitive advantage: An empirical analysis of their evolution. Journal of Business Research, 85, 32-50. doi: https://doi.org/10.1016/j.jbusres.2017.11.045.

Schilke, O. (2014). Second-order dynamic capabilities: How do they matter? Academy of Management Perspectives, 28(4), 368-380. doi: https://doi.org/10.5465/amp.2013.0093.

Simon, H.A. (1945). Administrative behavior, Macmillan, New York.

Schoenecker, T., \& Swanson, L. (2002). Indicators of firm technological capability: validity and performance implications. IEEE Transactions on Engineering Management, 49(1), 36-44.

Swaray, R., \& Salisu, A. A. (2018). A firm-level analysis of the upstream-downstream dichotomy in the oil-stock nexus. Global Finance Journal, 37, 199-218. doi: https://doi.org/10.1016/j. gfj.2018.05.007.

Teece, D. J. (2014). The foundations of enterprise performance: Dynamic and ordinary capabilities in an (economic) theory of firms. Academy of Management Perspectives, 28(4), 328-352. doi: https:// doi.org/10.5465/amp.2013.0116. 
Teece, D. J. (2018). Business models and dynamic capabilities. Long Range Planning, 51(1), 40-49. doi: https://doi.org/10.1016/j.lrp.2017.06.007.

Teece, D. J. (2019). A capability theory of the firm: An economics and (strategic) management perspective. New Zealand Economic Papers, 53(1), 1-43. doi: https://doi.org/10.1080/ 00779954.2017.1371208.

Tello-Gamarra, J., \& Zawislak, P. A. (2013). Transactional capability: Innovation's missing link. Journal of Economics Finance and Administrative Science, 18(34), 2-8. doi: https://doi.org/10.1016/S20771886(13)70017-9.

Tello-Gamarra, J., Hernani-Merino, M., \& Límaco-Mamani, B. I. (2017). Capacidad transaccional: Evidencias del sistema financiero peruano. Revista de Administração de Empresas, 57(1), 37-50. doi: https://doi.org/10.1590/s0034-759020170104.

Triguero, Á., Córcoles, D., \& Cuerva, M. C. (2013). Differences in innovation between food and manufacturing firms: An analysis of persistence. Agribusiness, 29(3), 273-292. doi: https://doi. org/10.1002/agr.21335.

Tseng, S. M., \& Lee, P. S. (2014). The effect of knowledge management capability and dynamic capability on organizational performance. Journal of Enterprise Information Management, 27(2), 158-179. doi: https://doi.org/10.1108/JEIM-05-2012-0025.

Vicente, M., Abrantes, J. L., \& Teixeira, M. S. (2015). Measuring innovation capability in exporting firms: The INNOVSCALE. International Marketing Review, 32(1), 29-51. doi: https://doi.org/ 10.1108/IMR-09-2013-0208.

Williamson, O. (1985). The economic institutions of capitalism, New York, NY: Free Press.

Williamson, O. (1999). Strategic research: governance and competence, Strategic Management Journal, 20(12), 1087-1108.

Whitfield, L., Staritz, C., Melese, A. T., \& Azizi, S. (2020). Technological capabilities, upgrading, and value capture in global value chains: Local apparel and floriculture firms in Sub-Saharan africa. Economic Geography, 96(3), 195-218. doi: https://doi.org/10.1080/00130095.2020.1748497.

Zawislak, P. A., Cherubini Alves, A., Tello-Gamarra, J., Barbieux, D., \& Reichert, F. M. (2012). Innovation capability: From technology development to transaction capability. Journal of Technology Management \& Innovation, 7(2), 14-27. doi: https://doi.org/10.4067/S071827242012000200002.

Zawislak, P.A., Alves, A.C., Tello-Gamarra, J., Barbieux, D., \& Reichert, F.M. (2013). Influences of the internal capabilities of firms on their innovation performance: a case study investigation in Brazil. International Journal of Management, 30(1), 329.

Zawislak, P. A., Gamarra, J.T., Alves, A.C., Barbieux, D., \& Reichert, F. M. (2014). The different innovation capabilities of the firm: further remarks upon the Brazilian experience. Journal of Innovation Economics Management, 1, 129-150.

Zhou, K. Z., \& Wu, F. (2010). Technological capability, strategic flexibility, and product innovation. Strategic Management Journal, 31(5), 547-561.

Zylbersztajn, D. (2017). Agribusiness systems analysis: Origin, evolution and research perspectives. Revista de Administração, 52(1), 114-117. doi: https://doi.org/10.1016/j.rausp.2016.10.004.

Author contributions are as follows: Leo, Ricardo Machado -; Conceptualization (Equal); Data curation (Equal); Formal analysis (Equal); Funding acquisition (Equal); Investigation (Equal); Methodology (Equal); Project administration (Equal); Resources (Equal); Software (Equal); Supervision (Equal); Validation (Equal); Visualization (Equal); Writing-original draft (Equal); Writing-review \& editing (Equal); Camboim, Guilherme Freitas; Conceptualization (Equal); Data curation (Equal); Formal analysis (Equal); Funding acquisition (Equal); Investigation (Equal); Methodology (Equal); Project administration (Equal); Resources (Equal); Software (Equal); Supervision (Equal); Validation (Equal); Visualization (Equal); Writing-original draft (Equal); Writing-review \& editing (Equal); Avila, Ariane 
RAUSP

57,1

82

Mello Silva; Conceptualization (Equal); Data curation (Equal); Formal analysis (Equal); Funding acquisition (Equal); Investigation (Equal); Methodology (Equal); Project administration (Equal); Resources (Equal); Software (Equal); Supervision (Equal); Validation (Equal); Visualization (Equal); Writing-original draft (Equal); Writing-review \& editing (Equal); Reichert, Fernanda Maciel; Conceptualization (Equal); Data curation (Equal); Formal analysis (Equal); Funding acquisition (Equal); Investigation (Equal); Methodology (Equal); Project administration (Equal); Resources (Equal); Software (Equal); Supervision (Equal); Validation (Equal); Visualization (Equal); Writing-original draft (Equal); Writing-review \& editing (Equal); Zawislak , Paulo Antônio; Conceptualization (Equal); Data curation (Equal); Formal analysis (Equal); Funding acquisition (Equal); Investigation (Equal); Methodology (Equal); Project administration (Equal); Resources (Equal); Software (Equal); Supervision (Equal); Validation (Equal); Visualization (Equal); Writing-original draft (Equal); Writing-review \& editing (Equal). 


\section{Appendix}

To what extent do you agree with the statements below? 1 means totally disagree and 5 completely agree.

\begin{tabular}{|c|c|c|}
\hline \multirow{7}{*}{$\begin{array}{l}\text { Development capability } \\
\text { (DC) }\end{array}$} & DC1 & Designs its own product base \\
\hline & DC2 & Monitors the latest tendencies in technology in the sector \\
\hline & DC3 & $\begin{array}{l}\text { Uses formal product management methods (stage-gate, PMBOK, } \\
\text { innovation funnel, etc.) }\end{array}$ \\
\hline & $\mathrm{DC} 4$ & Adapts the technology in use to its own needs \\
\hline & DC5 & Prototypes its own products \\
\hline & DC6 & Develops products in partnerships with science and technology institutions \\
\hline & DC7 & Launches its own products \\
\hline \multirow{9}{*}{$\begin{array}{l}\text { Operations capability } \\
\text { (OC) }\end{array}$} & $\mathrm{OC} 1$ & Formalizes the PPC procedures \\
\hline & OC2 & Keeps statistical control of the process \\
\hline & OC3 & Uses leading-edge technology in the sector \\
\hline & $\mathrm{OC} 4$ & Maintains adequate stock levels of materials for the process \\
\hline & OC5 & Carries out the productive process as programmed \\
\hline & OC6 & Establishes a productive routine that does not generate rework \\
\hline & OC7 & Delivers the product promptly \\
\hline & OC8 & Manages to expand the installed capacity whenever necessary \\
\hline & OC9 & Manages to ensure the process does not lead to products being returned \\
\hline \multirow{7}{*}{$\begin{array}{l}\text { Management capability } \\
\text { (MC) }\end{array}$} & $\mathrm{MC1}$ & Formally defines its strategic aims annually \\
\hline & $\mathrm{MC} 2$ & Uses technology to integrate all its sectors \\
\hline & MC3 & Standardizes and documents the work procedures \\
\hline & $\mathrm{MC4}$ & Updates its management tools and techniques \\
\hline & MC5 & $\begin{array}{l}\text { Maintains the personnel adequately trained for the company functions } \\
\text { (training) }\end{array}$ \\
\hline & MC6 & Uses modern financial management practices \\
\hline & MC7 & Includes social and environmental responsibilities on its strategic agenda \\
\hline \multirow{6}{*}{$\begin{array}{l}\text { Transaction capability } \\
\text { (TC) }\end{array}$} & $\mathrm{TC} 1$ & Conducts formal research to monitor the market \\
\hline & TC2 & Imposes its negotiating terms on its suppliers \\
\hline & TC3 & Imposes its prices on the market \\
\hline & $\mathrm{TC} 4$ & Imposes its negotiating terms on its customers \\
\hline & TC5 & Conducts research to measure its customers' satisfaction \\
\hline & TC6 & Uses formal criteria to select its suppliers \\
\hline \multirow[t]{3}{*}{ Innovative performance } & IP1 & The net profit has grown continuously over the past 3 years \\
\hline & IP2 & The company's market share has continuously grown over the past 3 yea \\
\hline & IP3 & The company's revenue has continuously grown over the past 3 years \\
\hline
\end{tabular}

DC4 Adapts the technology in use to its own needs

Prototypes its own products

DC7 Launches its own products

OC1 Formalizes the PPC procedures

OC3 Uses leading-edge technology in the sector

OC4 Maintains adequate stock levels of materials for the process

OC5 Carries out the productive process as programmed

OC7 Delivers the product promptly

OC8 Manages to expand the installed capacity whenever necessary

$\begin{array}{lll}\text { Management capability } & \text { MC1 } & \text { Formally defines its strategic aims annually } \\ \text { (MC) } & \text { MC2 } & \text { Uses technology to integrate all its sectors }\end{array}$

MC4 Updates its management tools and techniques

MC5 Maintains the personnel adequately trained for the company functions (training)

MC6 Uses modern financial management practices

Includes social and environmental responsibilities on its strategic agenda

Transaction capability

TC2 Imposes its negotiating terms on its suppliers

TC4 Imposes its negotiating terms on its customers

TC5 Conducts research to measure its customers' satisfaction

IP1 The net profit has grown continuously over the past 3 years

IP3 The company's revenue has continuously grown over the past 3 years

Table A1.

Research instrument

\section{Corresponding author}

Ricardo Machado Leo can be contacted at: ricardomachado_3@hotmail.com

Associate editor: Giancarlo Gomes

For instructions on how to order reprints of this article, please visit our website:

www.emeraldgrouppublishing.com/licensing/reprints.htm

Or contact us for further details: permissions@emeraldinsight.com 